\title{
Multilineage differentiation potential of cells isolated from the human amniotic membrane
}

\author{
Silvia Díaz-Prado, Emma Muiños-López, Tamara Hermida-Gómez, María Esther \\ Rendal-Vázquez, Isaac Fuentes-Boquete, Francisco J. de Toro, Francisco J. Blanco
}

\begin{abstract}
The human amniotic membrane (HAM) contains two cell types from different embryological origins. Human amnion epithelial cells (hAECs) are derived from the embryonic ectoderm, while human amnion mesenchymal stromal cells (hAMSCs) are derived from the embryonic mesoderm. In this study, we localized, isolated, quantified and phenotypically characterized HAM-derived cells and analysed their in vitro differentiation potential towards mesodermal cell lineages. Human amnion-derived cells were isolated and characterized by flow cytometry. Immunohistochemistry and quantitative real-time reverse transcription-polymerase chain reaction studies were performed for the analysis of multipotentiality. Immunophenotypic characterization of both cell types demonstrated the presence of the common, well-defined human mesenchymal stem cell (MSC) markers (CD90, CD44, CD73, CD166, CD105, CD29), as well as the embryonic stem-cell markers SSEA-4 and STRO-1. Phenotypes of both cell populations were maintained from passages $\mathrm{P} 0$ to $\mathrm{P} 9$. The assessment of multilineage potential demonstrated that the hAMSCs showed greater adipogenic and chondrogenic potential. Both populations had the ability to retain their capacity for differentiation during culture passages from P0 to P4. Our data demonstrate the successful localization and isolation of hAMSCs and hAECs from the HAM. Both cell populations possessed similar immunophenotype. However, they differed in cell yield and multipotential for differentiation into the major mesodermal lineages. Our functional differentiation studies demonstrated that hAMSCs possess a much greater mesodermal differentiation capacity than hAECs. These considerations will be important for use of these cells for cell therapy.
\end{abstract}

Key Words

Amniotic membrane; Choncrocytes; Cartilage; Cell therapy; Adipose tissue

Within the bone marrow stroma, a subset of non-hematopoietic cells referred to as mesenchymal stem cells (MSC) exists. These cells can be expanded ex vivo and induced, both in vitro or in vivo, to terminally differentiate into at least seven cell types: osteocytes, chondrocytes, adipocytes, tenocytes, myotubes, astrocytes and hematopoietic-supporting stroma [Minguell et al., 2000]. Three criteria define all types of stem cells: self-renewal, multipotency and the ability to reconstitute a tissue in vivo. Human MSCs, which are probably responsible for normal tissue renewal, as well as for response to injury [Tsai et al., 2007], can be isolated from bone marrow, peripheral blood, umbilical cord blood, umbilical cord, amniotic fluid, amniotic membrane, placenta, fat, skin, vasculature and muscle tissues.

Multipotent MSCs are a promising cell resource for tissue engineering and cell-based therapeutics because of their ability to self-renew and differentiate into specific functional cell types [Tsai et al., 2007]. The list of tissues with the potential for tissue engineering is increasing because of recent progress in stem-cell biology [Bianco and Robey, 2001].

The use of bone marrow, which is the traditional tissue source for adult MSCs, however, has some limitations. One of the most important is accessibility. The procedure required to obtain bone marrow is invasive, painful and associated with morbidity, the number of MSCs obtained is low and the potential to proliferate and differentiate diminishes as the donor's age increases [Baksh et al., 2007; Soncini et al., 2007; Ilancheran et al., 2009; Wei et al., 2009]. Thus, the identification of alternative MSC sources is necessary.

The human amniotic membrane (HAM) develops from extra-embryonic tissue and consists of a foetal component, the chorionic plate and a maternal component, the deciduas. The HAM is consists of an epithelial monolayer, a thick basement membrane and an avascular stroma [Jin et al., 2007; Niknejad et al., 2008]. The inner layer, the amnion, consists of a single layer of ectodermally derived epithelium uniformly arranged on the basement membrane, one of the thickest membranes found in any human 
tissue, and a collagen-rich mesenchymal layer [Wilshaw et al., 2006]. The HAM contains two cell types from different embryological origins [Alviano et al., 2007; Wolbank et al., 2007]. The human amnion epithelial cells (hAECs) are derived from embryonic ectoderm [Tamagawa et al., 2008], which forms a continuous monolayer in contact with the amniotic fluid. Human amnion mesenchymal stromal cells (hAMSCs) are derived from embryonic mesoderm [Tamagawa et al., 2008] and are sparsely distributed in the stroma underlying the amnion epithelium [Bilic et al., 2008]. This foetal tissue expresses only moderate levels of the major histocompatibility complex (MHC) class I and MHC class II antigens on its surface. Therefore, hAECs and hAMSCs seem to be immune-privileged, thus suitable for allotransplantation and regenerative medicine [Kim et al., 2009; Wei et al., 2009]. Bailo et al. 2004 isolated and characterized amnion and chorion cells from human full-term placentae, suggesting that both cell types represent a useful source of progenitor cells with potential applications for cell therapy and transplantation procedures.

Because foetal tissues are routinely discarded post-partum, HAMs have proved to be abundant, inexpensive and easily obtained with a virtually limitless availability, negating any need for mass tissue banking [Wilshaw et al., 2006; Hennerbichler et al., 2007; Toda et al., 2007; Niknejad et al., 2008; Chang et al., 2010]. Therefore, the HAM represents a very useful source of progenitor cells for a variety of applications. Because human embryos are not sacrificed for the isolation of progenitor cells from HAMs, the current controversies associated with the use of human embryonic stem cells can be avoided [Toda et al., 2007; Kim et al., 2009; Chang et al., 2010; Insausti et al., 2010].

In the present study, we performed the localization, isolation, quantification and phenotypic characterization of HAM-derived cells (hAECs and hAMSCs) and analysed their in vitro differentiation potential towards the osteogenic, adipogenic and chondrogenic cell lines useful for regenerative medicine and cell therapy.

\section{Materials and Methods}

\section{Harvest and Preparation of HAMs}

Human placentas from 12 healthy donor mothers were obtained from caesarean sections performed at the Hospital Materno Infantil-Teresa Herrera in A Coruña, Spain. All mothers gave written informed consent prior to collection. This study was approved by the Ethics Committee of Clinical Investigation of Galicia (Spain). Under stringent sterile conditions the harvested placentas were placed in 199 Medium (Invitrogen S.A., Barcelona, Spain) with antibiotics: cotrimoxazol $\left(50 \mu \mathrm{g} / \mathrm{ml}\right.$; Soltrim ${ }^{\circledR}$, AlmirallProdesfarma S.A., Barcelona, Spain), vancomycin $\left(50 \mu \mathrm{g} / \mathrm{ml}\right.$; Vancomicina Hospira ${ }^{\circ}$, Laboratorio Hospira S.L., Madrid, Spain), amykacin $\left(50 \mu \mathrm{g} / \mathrm{ml}\right.$; Amikacina Normon ${ }^{\circledR}$, Laboratorios Normon S.A., Madrid, Spain) and B amphotericin ( $5 \mu \mathrm{g} / \mathrm{ml}$; Fungizona ${ }^{\circledR}$, Bristol-Myers Squibb S.L., Madrid, Spain). The HAM was carefully separated from the chorion and immediately processed, following washes with $0.9 \% \mathrm{NaCl}$ solution three to five times to remove blood and mucus.

\section{Isolation and Culture of Human Amnion-Derived Cells: hAMSCs and hAECs}

The HAMs were then processed following the protocol of Soncini et al. 2007. The HAM was cut into approximately $2 \times 2 \mathrm{~cm}^{2}$ pieces and transferred into an enzymatic digestion buffer containing $2.4 \mathrm{U} / \mathrm{ml}$ of dispase (Gibco, Madrid, Spain) in phosphate buffered saline (PBS) and incubated at $37^{\circ} \mathrm{C}$ for $7 \mathrm{~min}$. The digested tissue was centrifuged and the supernatant was discarded. The tissue was then subjected to a second enzymatic digestion containing $0.75 \mathrm{mg} / \mathrm{ml}$ of type I clostridial collagenase (Gibco) and $20 \mu \mathrm{g} / \mathrm{ml}$ of deoxyribonuclease I (DNAse I; Sigma-Aldrich, Quimica S.A., Madrid, Spain) in RPMI 1640 (Lonza, Barcelona, Spain) culture medium for $3 \mathrm{~h}$ at $37^{\circ} \mathrm{C}$. Following this digestion the resulting cell suspension was filtered through a sterile $70 \mu \mathrm{m}$ filter (BD Biosciences, Madrid, Spain). The collected cells were designated as hAMSCs. Non-digested amnion fragments were incubated with a solution containing $0.25 \%$ trypsin-EDTA (Sigma-Aldrich) at $37^{\circ} \mathrm{C}$ for $2-3 \mathrm{~min}$. The resulting cell suspension, containing hAECs was centrifuged at $200 \mathrm{~g}$ for $10 \mathrm{~min}$. The cells were resuspended in Dulbecco's modified Eagle medium (DMEM; Sigma-Aldrich) with $20 \%$ foetal bovine serum (FBS; Lonza) and $1 \%$ penicillinstreptomycin (P/E; Gibco) and seeded into $162 \mathrm{~cm}^{2}$ culture flasks. Both hAECs and hAMSCs cells were cultured in a humidified $5 \% \mathrm{CO}_{2}$ atmosphere at $37^{\circ} \mathrm{C}$ until $70 \%$ confluent. The cells were then recovered and expanded to obtain the appropriate number of cells for further experiments. Non-adherent cells were removed after $48 \mathrm{~h}$ of culture. 


\section{Quantification of Cells}

The isolated hAMSCs and hAECs were counted using a Neubauer Chamber. Trypan blue dye (0.4\%; Sigma-Aldrich, St. Louis, MO, USA) was used to assess cell viability.

\section{Cell Characterization by Flow Cytometry}

HAM-derived cells were harvested by trypsinization, washed and centrifuged at $300 g$ for $8 \mathrm{~min}$. The cells were counted and $2 \times 10^{5}$ cells were transferred to fluorescence-activated cell sorting (FACS) polypropylene tubes before flow cytometry. The antibodies listed in Table I were used for these experiments. Optimal amounts of monoclonal antibodies (mAbs) were determined and added to each tube for $40 \mathrm{~min}$ at $4^{\circ} \mathrm{C}$ in darkness. Most antibodies were conjugated with fluorescein isothiocyanate (FITC), phycoerithrin (PE), or allophicocianine (APC) and were specific for the human markers associated with mesenchymal and hematopoietic lineages. When the use of a secondary antibody was necessary, the cells were incubated for $30 \mathrm{~min}$ at $4^{\circ} \mathrm{C}$ in darkness to allow its binding to the primary antibody. A control tube for each of the chromogens used contained equivalent amounts of isotype standards. A minimum of 10,000 cell events per assay were acquired on a FACsCalibur flow cytometer (BD Biosciences). Data were analysed using Cell Quest software (BD Biosciences). Statistical evaluations were performed using the Mann-Whitney $U$-test. Results are expressed as percent positive, that is, mean \pm standard deviation (mean $\pm \mathrm{SD}$ ). Differences were considered statistically significant when $P<0.05$.

Table I. Antibodies Used for Cell Characterization by Flow Cytometry

\begin{tabular}{llll}
\hline Antibody & Specificity & Clone & Source \\
& & & \\
R-PE-CD29 & B1 Integrin & MAR4 & BD Pharmingen \\
R-PE-CD34 & Hemopoietic progenitor cell antigen 1 (HPCA1) & 581 & BD Pharmingen \\
FITC-CD44 & HCAM & IM7 & BD Pharmingen \\
FITC-CD45 & Leukocyte common antigen (LCA) & HI30 & BD Pharmingen \\
PE-CD73 & Ecto-5'-nucleotidase & AD2 & BD Pharmingen \\
PE-Cy5-CD90 & Thy-1 & 5E10 & BD Pharmingen \\
FITC-CD105 & Endoglin & SN6 & Serotec \\
APC-CD117 & c-kit, SCFR & YB5.B8 & BD Pharmingen \\
R-PE-CD166 & ALCAM & 3 A6 & BD Pharmingen \\
Fibroblast & Fibroblast-specific antigen & 1B10 & Sigma Aldrich Quimica \\
SSEA-4 & Stage-specific embryonic antigen 4 & MC-813-70 & R\&D Systems \\
STRO-1 & Stromal antigen 1 & NS1-Ag4-1 & Developmental Studies Hybridoma Bank \\
& & & \\
\hline
\end{tabular}

\section{In Vitro Differentiation Studies}

\section{Adipogenesis.}

hAECs and hAMSCs from the passages P0 to P4 were detached using trypsin-EDTA and $1.5 \times 10^{5}$ cells $/ \mathrm{cm}^{2}$ were cultured in a one-well chamber slide in growth medium until confluent. Adipogenesis was induced by culturing in Bullekit Adipogenic Differentiation Medium (Lonza), following the manufacturer's instructions. Cells were fixed for histological analysis using $4 \%$ paraformaldehyde.

Osteogenesis

HAM-derived cells from passages P0 to P4 were detached using trypsin-EDTA and $1.5 \times 10^{5} \mathrm{cells} / \mathrm{cm}^{2}$ were cultured in a one-well chamber slide in growth medium until confluent. Osteogenesis was induced by culturing for 3 weeks in hMSC Bullekit Osteogenic Differentiation Medium (Lonza). The culture medium was changed every 2-3 days. Cells were fixed in $4 \%$ paraformaldehyde for histological analysis. 
Chondrogenesis

Chondrogenesis was assessed by micropellet formation as described by Johnstone et al. 1998, with some modifications. HAM-derived cells $\left(5 \times 10^{5}\right.$ cells $\left./ \mathrm{cm}^{2}\right)$ from passages P0 to P4 were detached using trypsin-EDTA and centrifuged at $300 \mathrm{~g}$ for $10 \mathrm{~min}$. The resulting pellet was cultured in chondrogenic differentiation medium [Arufe et al., 2009], DMEM with 15\% FBS. The medium was supplemented with $5 \mathrm{mg} / \mathrm{ml}$ ascorbic acid (AA), 1/1,000 monotioglycerol (MTG) and 1\% P/E during the first 2 days to promote the induction of chondrogenesis. The medium was then replaced by DMEM with $15 \%$ knockout serum (Gibco), $1 \% \mathrm{P} / \mathrm{E}$ and supplemented with $1 \mu \mathrm{l} / \mathrm{ml}$ AA, $10 \mu \mathrm{M}$ dexamethasone (DEXA), $6 \mu \mathrm{l} / \mathrm{ml}$ Transferrin, $1 \times 10^{7} \mathrm{M}$ retinoic acid (RA) and $1 \mathrm{ng} / \mathrm{ml}$ of recombinant human transforming growth factor$\beta 3$ (rHuTGF- $\beta 3$; Prospec-Tany Technogene Ltd., Rehovot, Israel) for 21 days. The medium was changed every 2-3 days. The micropellets were embedded in paraffin and the presence of hyaline cartilagecharacteristic molecules [collagen type II (Coll II) and proteoglycans] was detected using the histological and immunohistochemical techniques described below.

For controls for each differentiation assay, hAECs and hAMSCs were cultured in DMEM medium containing 20\% FBS and P/E for 21 days. The controls were also evaluated using the same histological and immunohistochemical analyses.

\section{Histological Analyses}

To evaluate chondrogenesis, 4- $\mu \mathrm{m}$ thick paraffin sections of the micropellets were deparaffinized in xylol, rehydrated in a graded series of ethanol, and stained with hematoxylin and eosin (H\&E), Masson's trichrome and toluidine blue (for proteoglycans). To evaluate osteogenesis, the presence of calcium deposits was determined using Alizarin Red stain according to the standard protocol. To evaluate adipogenesis, the presence of cytoplasmic lipid droplets in the cultures was visualized using Oil Red O stain. Quantification of the staining for Alizarin Red and Oil Red $\mathrm{O}$ was performed using analiSIS ${ }^{\circ}$ software (version D; Olympus, Barcelona, Germany).

\section{Immunohistochemical Analyses}

For the immunohistochemical evaluation of chondrogenesis, 4- $\mu \mathrm{m}$ thick paraffin sections, deparaffinized, and hydrated as described above, were incubated with mAbs to detect the presence of Coll I (Abcam, Cambridge, UK) and Coll II (Neomarker, Barcelona, Spain), and with a polyclonal antibody to detect aggrecan (Agg; C-20; Santa Cruz Biotechnology, Heidelberg, Germany; Table II). To facilitate exposure of the epitopes, sections were pre-treated with proteinase K (Sigma-Aldrich). The peroxidase/DAB ChemMateTM DAKO EnVisionTM detection kit (Dako, Barcelona, Spain) was used to determine antigen-antibody interactions. Localization of MSC-derived amniotic cells by immunofluorescence was performed using antibodies listed in Table II. Negative staining controls omitted the primary mAb. Quantification of the immunostaining for Coll I and II and Agg was performed using analiSIS® software (version D; Olympus, Barcelona, Germany).

Table II. Antibodies Used for Immunoenzymatic and Immunofluorescence Studies

\begin{tabular}{lll}
\hline Specificity & Clone & Source \\
\hline Inmunoenzymatic & & \\
Type I collagen & COL-1 & Abcam \\
Type II collagen & $6 B 3$ & Neomarker \\
Aggrecan (C-20) & Polyclonal & Santa Cruz Biotechnology \\
Inmunofluorescence & & \\
CD44 & HCAM & Santa Cruz Biotechnology \\
CD90 & SE10 & BD Pharmingen \\
CD105-FITC & SN6 & Serotec \\
CD271 & ME20.4 & Sigma Aldrich \\
& & \\
\hline
\end{tabular}




\section{RNA Extraction}

Isolation of total RNA from cell cultures was performed using Trizol Reagent (Invitrogen), following the manufacturer's protocol. From each cell culture, $2.5 \times 10^{5}$ cells were extracted for RNA isolation. Total RNA was further processed by reverse transcription-polymerase chain reaction (RT-PCR) or stored at $-80^{\circ} \mathrm{C}$ until used. RNA integrity was confirmed by $2 \%$ agarose gel electrophoresis stained with ethidium bromide. RNA also was assessed for quantity at $260 \mathrm{~nm}$ using a NanoDrop ${ }^{\mathrm{TM}}$ spectrophotometer (Thermo Scientific, Madrid, Spain). The A260/A280 ratio was calculated to verify quality and purity.

\section{cDNA Synthesis}

RT-PCR was accomplished from $1 \mu \mathrm{g}$ of total RNA using SuperScript ${ }^{\text {TM }}$ First-Strand Synthesis System for RT-PCR (Invitrogen) in a total volume of $20 \mu \mathrm{l}$ in a Thermocycler (Gene Amp PCR System 9700, Applied Biosystems, Madrid, Spain). One microgram of total RNA, $25 \mathrm{nM}$ Oligo(dT), $0.5 \mathrm{mM}$ of dNTP mix, and $3 \mu \mathrm{l}$ of DEPC-treated water were denatured at $65^{\circ} \mathrm{C}$ for $5 \mathrm{~min}$ and chilled on ice for at least $1 \mathrm{~min}$. In addition, $2 \mu \mathrm{l}$ of $10 \times \mathrm{RT}$ buffer, $5 \mathrm{mM} \mathrm{MgCl}_{2}, 0.01 \mathrm{M} \mathrm{DTT}$, and $40 \mathrm{U}$ of RNaseOUT Recombinant Ribonuclease Inhibitor were mixed, collected by centrifugation, and incubated at $25^{\circ} \mathrm{C}$ for $2 \mathrm{~min}$. After incubation, $50 \mathrm{U}$ of SuperScript ${ }^{\mathrm{TM}} \mathrm{RT}$ were added and incubated at $25^{\circ} \mathrm{C}$ for $10 \mathrm{~min}, 42^{\circ} \mathrm{C}$ for $50 \mathrm{~min}$ and $70^{\circ} \mathrm{C}$ for $15 \mathrm{~min}$ in a Thermocycler (Gene Amp PCR System 9700, Applied Biosystems). Finally, the samples were chilled on ice and incubated with $2 \mathrm{U}$ of RNAse $\mathrm{H}$ for $20 \mathrm{~min}$ at $37^{\circ} \mathrm{C}$ before proceeding to amplification of the target cDNA.

Samples were stored at $-20^{\circ} \mathrm{C}$ before target cDNA was amplified. Positive and negative controls were included in each experiment. RNA extraction, RT-PCR assay setup and post RT-PCR product analysis were carried out in separate dedicated rooms to prevent cross-contamination.

\section{Quantitative Real-Time RT-PCR Analysis ( $q R T-P C R$ )}

qRT-PCR analysis was performed, using the primers and conditions shown in Table III, on a LightCycler® 480 Instrument (Roche, Mannheim, Germany) using LightCycler 480 SYBR Green I Master (Roche).

Table III. Primer Sequences, Conditions and Annealing Temperatures of Real-Time Reverse Transcription-Polymerase Chain Reaction (RT-PCR) for Amplification of mRNA Human Genes Specific for Adipogenic, Osteogenic and Chondrogenic Differentiation

\begin{tabular}{|c|c|c|c|c|c|c|}
\hline Primer & Sequence & Position & $\begin{array}{l}\text { Length } \\
\text { (mer) }\end{array}$ & $\% \mathrm{GC}$ & $\begin{array}{l}\text { Annealing } \\
\text { temperature }\left({ }^{\circ} \mathrm{C}\right)\end{array}$ & $\begin{array}{l}\text { Amplicon } \\
\text { (bp) }\end{array}$ \\
\hline Sox9 2R & $5^{\prime}$-tcgctctcottcagaagtctc-3' & $801-821$ & 21 & 52 & & \\
\hline COL2A13F & $5^{\prime}$-gtgtcagggccaggatgt-3' & $247-264$ & 18 & 61 & 61 & 116 \\
\hline COL2A1 3R & $5^{\prime}$-tcccagtgtcacagacacagat- $3^{\prime}$ & $341-362$ & 22 & 50 & & \\
\hline FABP4 1F & 5 -ggatgataaactggtggtgga-3' & $401-421$ & 21 & 48 & 61 & 125 \\
\hline FABP4 1R & $5^{\prime}$-cacagaatgttgtagagttcaatgc-3' & $501-525$ & 25 & 40 & & \\
\hline APM $11 \mathrm{~F}$ & $5^{\prime}$-ggtgagaaaggagatccaggt- $3^{\prime}$ & $280-300$ & 21 & 52 & 61 & 147 \\
\hline APM1 1R & $5^{\prime}$-tgctgagcggtatacataggc-3' & $406-426$ & 21 & 52 & & \\
\hline LPL $1 F$ & $5^{\prime}$-agaacatcccattcactctgc-3' & $1491-1511$ & 21 & 48 & 61 & 107 \\
\hline OP $1 \mathrm{R}$ & $5^{\prime}$-ggctgtcccaatcagaagg-3' & $763-781$ & 19 & 58 & & \\
\hline RPLP $1 F$ & $5^{\prime}$-cctggaagtccaactacttcctta-3' & $260-283$ & 24 & 46 & 61 & 143 \\
\hline RPLP 1R & $5^{\prime}$-catcagcaccacagccttc- $3^{\prime}$ & $384-402$ & 19 & 58 & & \\
\hline
\end{tabular}

\%GC, percentage of guanine-cytosine; Sox9, sex-determining region Y-box 9; Col2A1, collagen type II alpha 1; Agg, aggrecan; FABP4, fatty acid-binding protein 4; APM1, adiponectine; LPL, lipoprotein lipase; ALP, alkaline phosphatase; OP, osteopontin; RPLP, 60S acidic ribosomal protein P0 (housekeeping gene). 
The PCR reaction consisted of $10 \mu \mathrm{l}$ of Master Mix $(2 \times), 0.35 \mu \mathrm{M}$ of each forward and reverse primer, cDNA template and PCR-grade water up to a final volume of $20 \mu \mathrm{l}$ in the LightCycler 480 Multiwell Plate 96 . An initial activation at $95^{\circ} \mathrm{C}$ for $10 \mathrm{~min}$ was followed by an amplification target sequence of 50 cycles at $95^{\circ} \mathrm{C}$ for $10 \mathrm{~s}, 61^{\circ} \mathrm{C}$ for $5 \mathrm{~s}$, and $72^{\circ} \mathrm{C} 7 \mathrm{~s}$. For the melting curve analysis, one cycle at $95^{\circ} \mathrm{C}$ for $5 \mathrm{~s}, 65^{\circ} \mathrm{C}$ for $1 \mathrm{~min}$, and $97^{\circ} \mathrm{C}$ for $1 \mathrm{~s}$ was used. The final cooling step was at $40^{\circ} \mathrm{C}$ for $20 \mathrm{~s}$.

The use of $2 \%$ agarose gel electrophoresis, stained with SYBR ${ }^{\circledR}$ Safe DNA gel stain (Invitrogen ${ }^{\mathrm{TM}}$ ), of all PCR products revealed a single band that corresponded to the single-amplified products as predicted by the PCR melting curve analysis.

PCR primers for mRNA amplification were carefully designed using the web-based ProbeFinder software (Universal ProbeLibrary Design Center, 2008) accessible at www.universalprobelibrary.com or at the Roche Applied Science home page (2008, www.roche-applied-science.com).

The selection of a suitable housekeeping gene was performed using the Human Endogenous Control Gene Panel (TATAA Biocenter, Göteborg, Sweden). The Excel macro named GeNorm VBA applet for Microsoft Excel (2006, available at http://medgen.ugent.be/ jvdescomp/genorm/) was used to determine the gene(s) with the most correlated expression in the set of samples. The housekeeping gene selected was RPLP (60s acidic ribosomal protein P0). Data analysis utilized the LightCycler 480 Relative Quantification software (Roche). Relative levels of expression were calculated by the $2^{-\Delta \Delta \mathrm{Ct}}$ method [Livak and Schmittgen, 2001]. Data were normalized against the value obtained in controls grown in DMEM culture medium at time 0 , which was considered equal to 1 , and were measured as relative expression levels (REL).

\section{DNA Sequencing Analysis}

At least one PCR product coming from each real-time PCR experiment was used as a template DNA. PCR products were purified by an enzymatic method (ExoSAP-IT, Amersham Biosciences, Madrid, Spain). DNA sequencing was performed in a reference facility on the ABI 3100 (Applied Biosystems) using Big Dye terminators. Forward and Reverse specific primers were used (these primers were the same as for the qRT-PCR experiments, see Table III).

\section{Other Procedures}

Standard procedures for manipulation of nucleic acids were essentially those of Sambrook et al. 1989.

\section{Statistical Analysis}

All statistical analyses were performed using SPSS 16.0 software for Windows; $P$-values $<0.05$ were considered to be statistically significant.

\section{Results}

\section{Localization of HAM-Derived Stem Cells}

To ascertain the histological localization of HAM-derived stem cells, four healthy HAMs were examined using immunofluorescence. The co-localization of the CD44, CD90, CD105 and CD271 stem-cell markers were assessed. We did not observe any cells in which co-localization of three and/or four stemcell markers occurred. However, we frequently observed co-localization of double markers. We found CD105 co-located with CD90, CD44 co-located with CD90 and CD271 co-localized with CD44 (Fig. 1). Most cells labelled with the different stem-cell markers were hAMSCs from the thick basement membrane, although in some membranes we observed hAECs, derived from the embryonic ectoderm, that were labelled only for the CD105 marker. The immunofluorescence results indicate that the HAM contains at least two different cell types having stem-cell characteristics. 

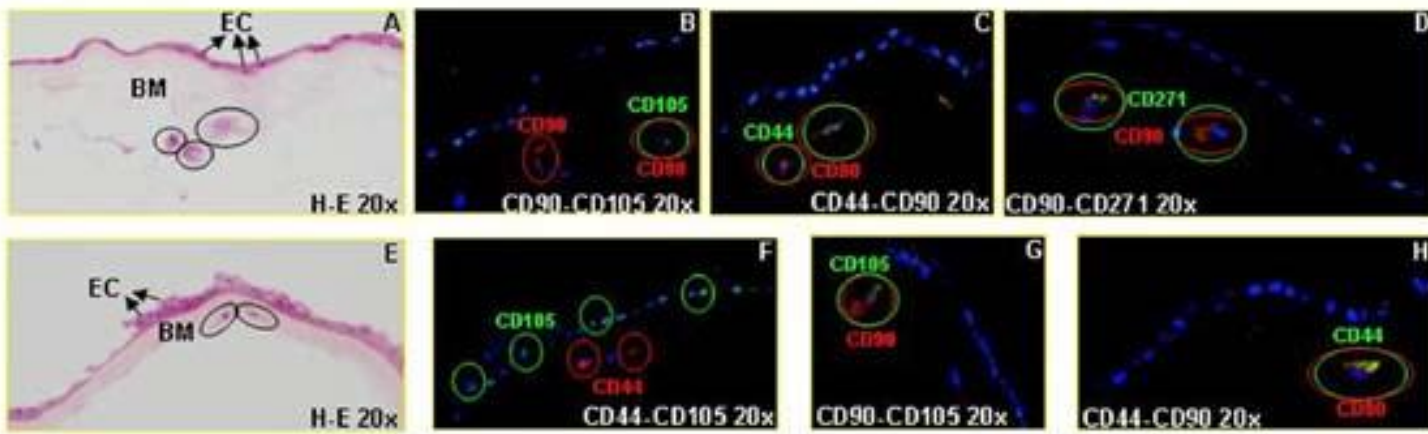

Figure 1. Immunofluorescence analysis of stem-cell marker expression of human amnion cells. Sections of four HAMs stained with H\&E (A and E). Representative images of hAMSCs and hAECs that were stained with antibodies specific for CD44, CD90, CD105 and CD271 (B-D and F-H) are shown. Nuclei were counterstained with 4',6-diamidino-2-phenylindole (DAPI). Immunofluorescence confirmed that hAMSCs were positive for CD44, CD90, CD105 and CD271, while hAECs were positive only for CD105. A thick basement membrane (BM) and cells from the extra-embryonic ectoderm (EC) are indicated. Circles highlight amnion cells from the basement membrane.

\section{Isolation of HAM-Derived Cells}

HAM-derived cells were isolated from full-term amnion after manual separation from the chorion. For cell isolation, we followed the protocol described by Soncini et al. 2007. This protocol resulted in the isolation of two distinct cell populations. One population had a fibroblast-like cell morphology and was considered to be hAMSCs derived from the embryonic mesoderm. The second population consisted of small-size cells that grew in a lattice with the typical quadrangular shape of epithelial cells and were considered to be hAECs derived from the embryonic ectoderm. After 2 days in culture, both hAECs and hAMSCs were attached to the culture flasks. Quantitative studies showed that this isolation protocol yielded $6.9 \times 10^{6} \pm 8.8 \times 10^{6}$ hAECs $(\mathrm{n}=3)$ and $2 \times 10^{6} \pm 2.4 \times 10^{6}$ hAMSCs $(\mathrm{n}=3)$.

\section{Phenotypical Characterization of HAM-Derived Cells}

Immunophenotypic analysis was performed to assess the expression of mesenchymal and hematopoietic markers in isolated hAECs and hAMSCs. This analysis was performed on cells after isolation at passages $\mathrm{P} 0-\mathrm{P} 2$. The expression profiles of these cells are shown in Table IV. Although we found markers specific for stem cells in both cell populations, there were no differences in expression profiles depending on the passage analysed.

Table IV. Analysis of Hematopoietic and Standard Adult Stem-Cell Markers on Human Amnion Mesenchymal Stromal Cells (hAMSCs) and Human Amnion Epithelial Cells (hAECs)

\begin{tabular}{lll}
\hline Marker & hAMSCs \% (mean \pm SD) & hAECs \% (mean \pm SD) \\
\hline & & $90.73 \pm 7.55$ \\
CD29 & $82.16 \pm 21.04$ & $21.74 \pm 21.32$ \\
CD44 & $76.11 \pm 20.16 \mathrm{a}$ & $80.88 \pm 10.24 \mathrm{a}$ \\
CD73 & $64.34 \pm 19.21$ & $47.54 \pm 30.15$ \\
CD90 & $88.44 \pm 11.47 \mathrm{a}$ & $11.52 \pm 6.70$ \\
CD105 & $31.83 \pm 29.8$ & $70.58 \pm 31.97$ \\
CD166 & $44.36 \pm 27.72$ & $14.31 \pm 7.04$ \\
CD117 & $22.78 \pm 16.68$ & $61.91 \pm 36.87$ \\
SSEA-4 & $37.82 \pm 40.03$ & $5.14 \pm 5.08$ \\
STRO-1 & $1.29 \pm 2.13$ & $0.02 \pm 0.04$ \\
CD34 & $0.175 \pm 0.39$ & \\
\hline
\end{tabular}


FACS analysis demonstrated that CD90 (88.48\% \pm 11.49$),$ CD44 (76.11\% \pm 20.16$),$ CD73 $(64.34 \% \pm 19.21), \mathrm{CD} 166(44.36 \% \pm 27.72), \mathrm{CD} 105(31.83 \% \pm 29.80), \mathrm{CD} 29(82.16 \% \pm 21.04)$ and CD117 $(22.78 \% \pm 16.68)$ are present in hAMSCs $(n=8)$. On the other hand, hAECs $(n=8)$ exhibit the presence of CD90 (47.54\% \pm 30.15$), \quad$ CD44 (21.74\% \pm 21.32$), \quad$ CD73 (80.88\% \pm 10.24$),$ CD166 $(70.58 \% \pm 31.97), \operatorname{CD} 105(11.52 \% \pm 6.7), \operatorname{CD} 29(90.73 \% \pm 7.55)$ and CD117 (14.31\% \pm 7.04$)$. The hematopoietic markers CD34 and CD45 were absent in both populations, indicating no contamination with hematopoietic stem cells from the umbilical cord blood. The absence of fibroblasts also indicated lack of contamination from embryonic fibroblasts.

When comparing the different markers among the two isolated populations, we observed that the expression levels of CD90 and CD44 were higher in hAMSCs than in hAECs $(P=0.012$ and 0.001 , respectively, Mann-Whitney $U$-test). However, CD73 showed higher levels of expression in hAECs than in hAMSCs $(P=0.015$, Mann-Whitney $U$-test $)$. There were no statistically significant differences among hAMSCs and hAECs in expression of the other markers. Interestingly, two embryonic stem-cell markers, SSEA-4 and STRO-1, were also found to be positive in both cell populations. The SSEA-4 marker was present at higher levels in the hAECs $(61.91 \%)$ than in hAMSCs $(37.82 \% ; P>0.05)$. The STRO-1 marker was also present at higher levels in hAECs $(5.14 \%)$ than in hAMSCs $(1.29 \%)$, although the differences were not significant statistically.

This phenotypical characterization demonstrated that HAM-derived cells, hAMSCs and hAECs, have a cell-surface receptor expression pattern similar to that previously reported for bone marrow MSCs. Interestingly, we found that both populations retained their phenotypic characteristics for at least nine culture passages.

\section{In Vitro Differentiation Potential of hAMSCs and hAECs}

Isolated hAMSCs and hAECs were cultured under specific conditions to perform functional differentiation assays. We studied the potential of these cells to differentiate into multiple cells lineages, specifically, chondrocytes, adipocytes and osteocytes, as previously described in Materials and Methods Section. As expected the differentiation potential studies showed the existence of donor-dependent variance.

Adipogenic differentiation was assessed by Oil Red $\mathrm{O}$ staining after 21 days of culture in adipogenic medium (Fig. 2). hAMSCs showed positive staining, with single adipocytic multivacuolar cells secreting lipid droplets. However hAECs displayed the absence or much weaker staining for lipids than hAMSCs. The percentage of cells with positive Oil Red O staining was 37 times higher in hAMSCs than in hAECs $(P$-value $=0.013$, Mann-Whitney $U$-test $)$. The same cells maintained in control medium (DMEM) exhibited almost no lipid deposits. 
A

DMEM 21

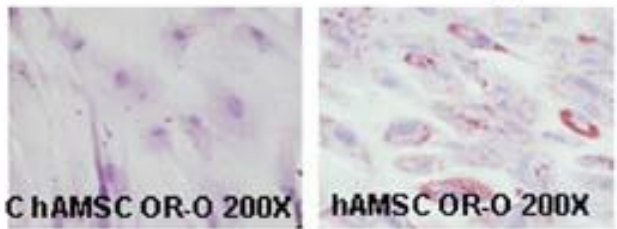

DMEM 21

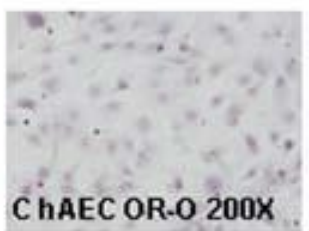

DIF Adipo

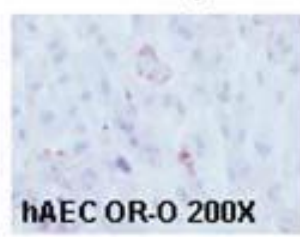

B

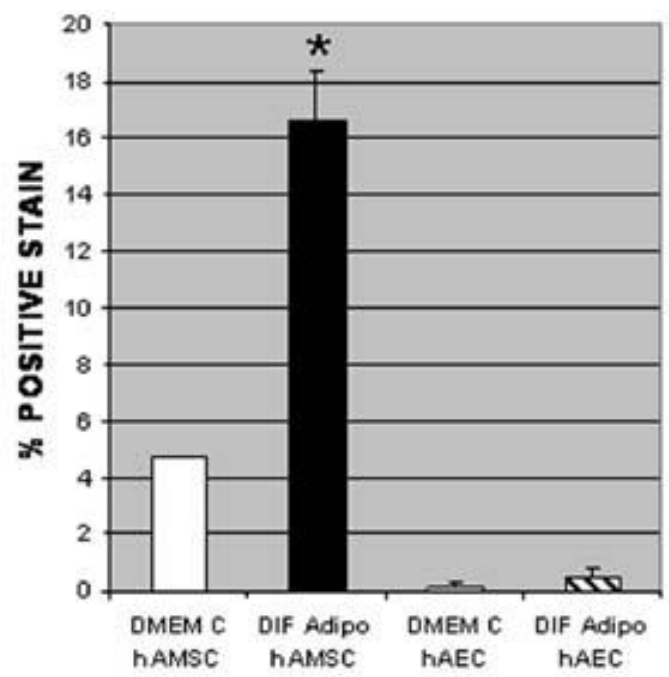

C

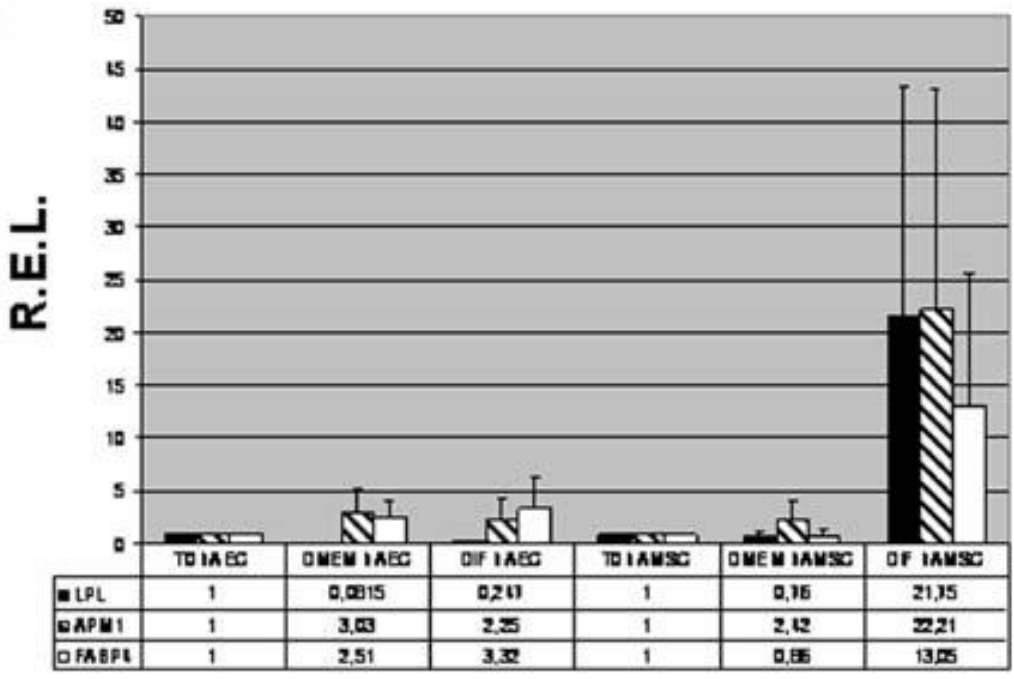

Figure 2. Adipogenic differentiation (Dif Adipo) of human amnion mesenchymal stromal cells (hAMSCs) and human amnion epithelial cells (hAECs) with their respective controls (C hAMSC and C hAEC) grown for 21 days in Dulbecco's modified Eagle medium (DMEM). The presence of adipocytes was assessed by detection of lipid drops using Oil Red O (OR-O) stain. The presence of the calcium deposits characteristic of osteoblasts was detected using Alizarin Red (AR) stain (A). The percentage of cells positive for OR-O stain is expressed as the mean \pm standard deviation; *Indicates $P<0.05$ (B). The adipogenic differentiation potential was confirmed by qRT-PCR, comparing results to the corresponding control time zero (T0) and DMEM-only culture. T0 data represent the expression of the different lineage-specific genes at the start of the experiment when the cells had not been stimulated to differentiate. DMEM data represent the expression of the different lineage-specific genes in cells cultured for 21 days in DMEM medium alone. DIF data represent the expression of the different lineage-specific genes in cells after culture for 21 days in a differentiation medium. mRNA levels were measured by qRT-PCR as described in Materials and Methods Section. Data are expressed as mean \pm standard error of the relative expression levels (REL). The results were normalized to values obtained for each cell population at the starting point of the experiment, which were considered to equal 1 (C). 
The osteogenic differentiation potential of HAM-derived cells was examined by determining the presence of calcification using Alizarin Red stain (Fig. 3). Both cell populations evidenced calcium deposition (hAMSCs: $13.63 \%$ and hAECs: $23.49 \%$ positive). Although hAECs manifested more intense staining levels these differences were not statistically significant. The same cells maintained in control medium presented an absence of calcium deposits.

A

\section{OSTEOGENESIS}

DMEM 21

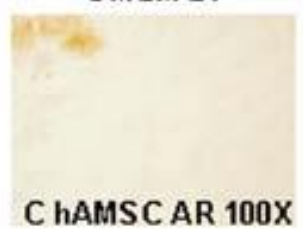

DIF Osteo

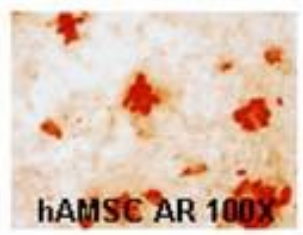

DMEM 21

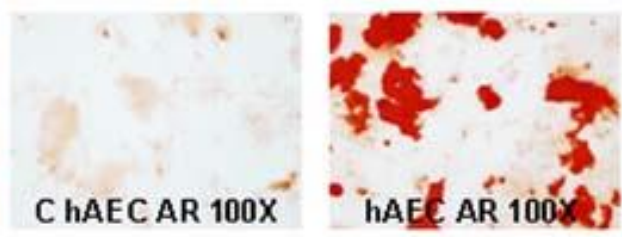

B

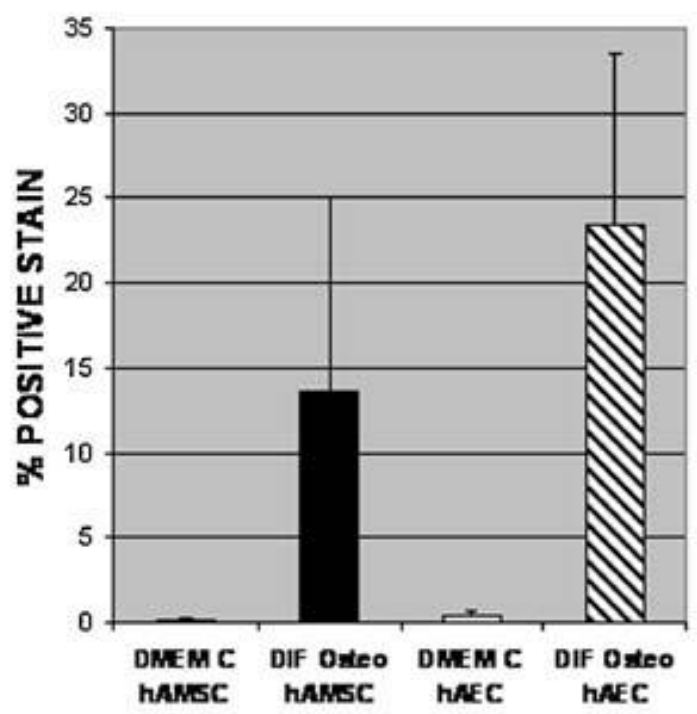

C

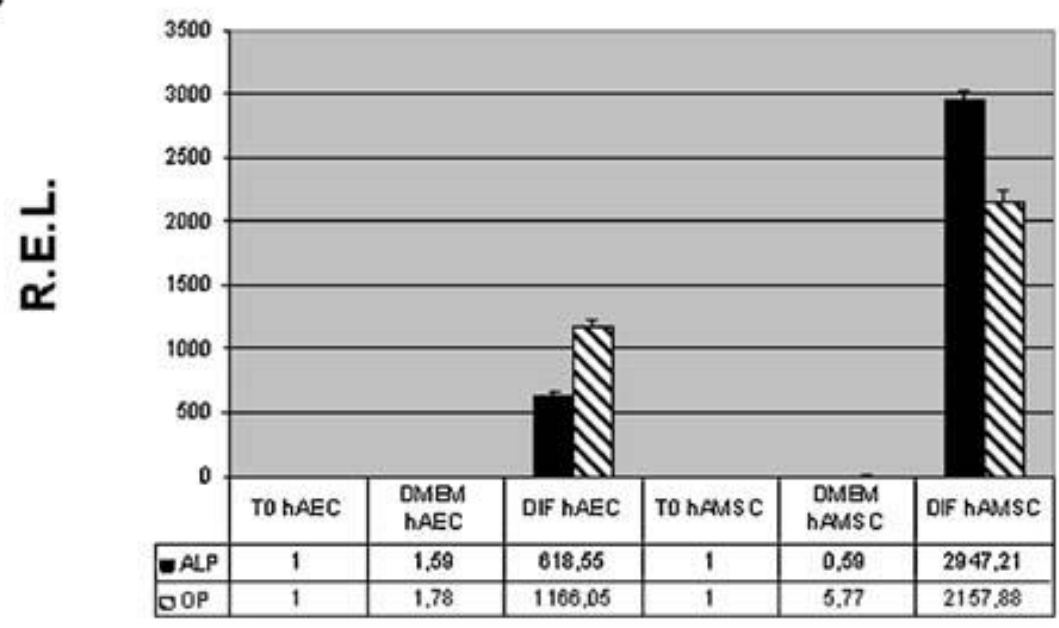

Figure 3. Osteogenic differentiation (Dif Osteo) of human amnion mesenchymal stromal cells (hAMSCs) and human amnion epithelial cells (hAECs) and their respective controls (C hAMSC and C hAEC) grown for 21 days in Dulbecco's modified Eagle medium (DMEM). The presence of calcium deposits characteristic of osteoblasts was detected using Alizarin Red (AR) stain (A). The percentage of cells positive for AR staining is expressed as the mean \pm standard deviation (B). The osteogenic differentiation potential was confirmed by qRT-PCR (C). 
The ability to undergo chondrogenic differentiation was assessed by toluidine blue staining for proteoglycans. Agg and Coll I and II were detected by immunohistochemisry (Fig. 4). Chondrogenesis was observed in all the cell preparations that were analysed. However, there were differences in the chondrogenic differentiation assays between the cell populations. The percentage of positive staining for Coll II and Agg were statistically significantly higher in hAMSCs than in hAECs $(P=0.015$ and 0.000$)$, respectively; Mann-Whitney $U$-test). However, it is important to note that some micropellet structures of hAECs did not acquire the typical round shape of chondrogenic differentiation described by Johnstone et al. 1998. Coll II and proteoglycans were detected throughout the newly formed matrix, although immunodetection for Agg was weak in most samples. Staining for Coll I was also weak or absent.

\section{CHONDROGENESIS}
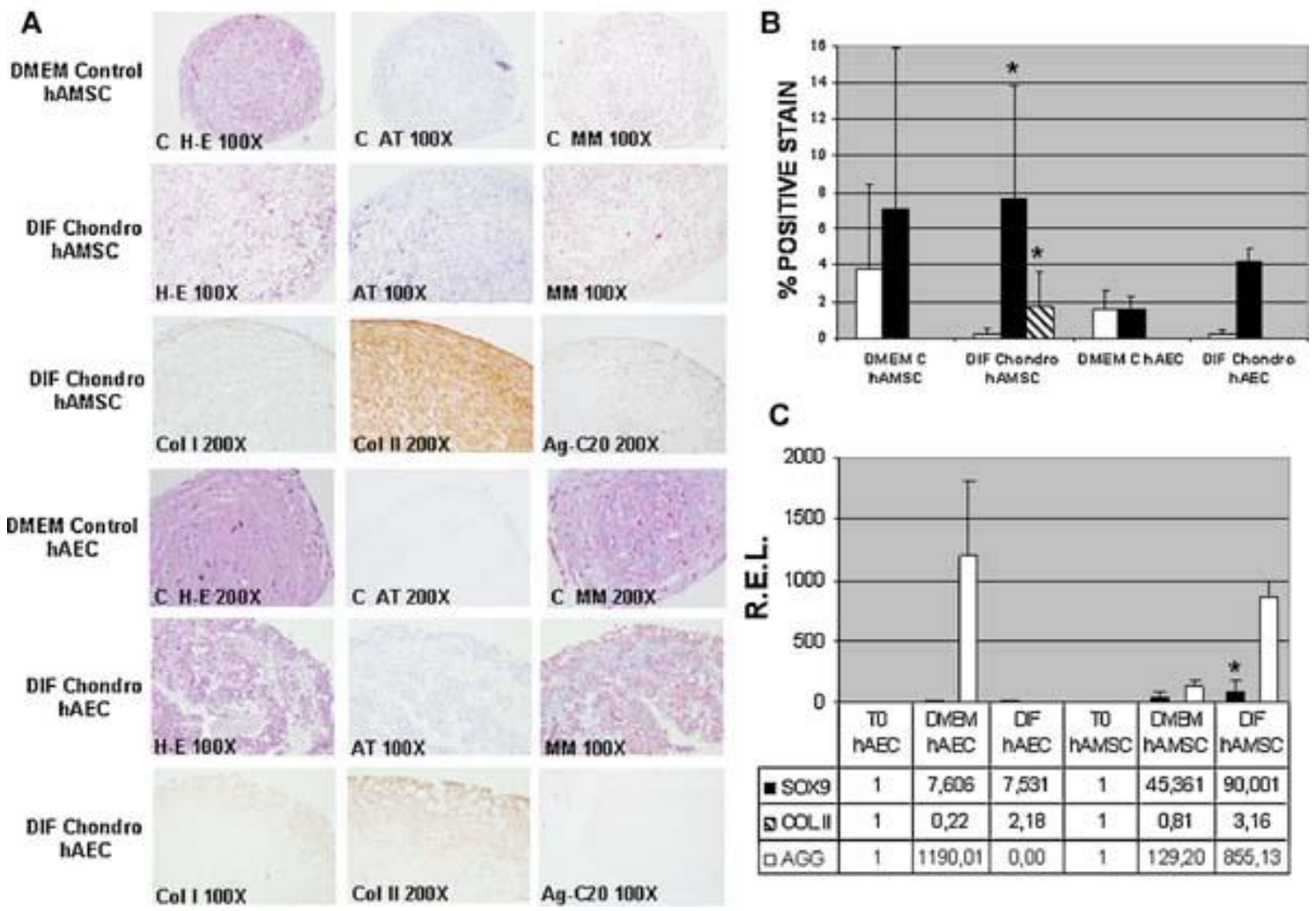

Figure 4. Chondrogenic differentiation (Dif Chondro) of human amnion mesenchymal stromal cells (hAMSCs) and human amnion epithelial cells (hAECs) and their respective controls (C hAMSC and hAEC) grown for 21 days in Dulbecco's modified Eagle medium (DMEM). Micropellets were stained with H\&E, Masson's trichrome (MM), and toluidine blue (AT) for proteoglycans. Immunodetection of $\mathrm{Agg}(\mathrm{Ag}-\mathrm{C} 20)$ and collagen type II (Col II) was performed to detect molecules characteristic of hyaline cartilage. Immunodetection for Col I was also assessed (A). The percentage of cells positive for Col I, Col II and Agg staining is expressed as the mean \pm standard deviation (B). The chondrogenic differentiation potential was confirmed by $q R T-P C R$ (C). *Indicates $P<0.05$.

Adipogenic, osteogenic and chondrogenic differentiation was also assessed by qRT-PCR. We studied the expression of some lineage-specific genes to determine which cell population, hAMSCs or hAECs, possessed the greater capability to differentiate. Expression levels of adiponectine (APM1), lipoprotein lipase (LPL) and fatty acid binding protein 4 (FABP4) were analysed for adipogenic differentiation. Expression levels of osteopontin (OP), and alkaline phosphatase (ALP) were analysed for osteogenic differentiation, and expression levels of Col II, Sox9 (sex determining region Y-box 9) and Agg were analysed for chondrogenic differentiation. RNA extracted from hAMSCs and hAECs following adipogenic, osteogenic and chondrogenic differentiation showed expression of all the lineage-specific genes analysed as shown in Figures 2C, 3C and 4C, with the exception being the lack of Agg in hAECs following chondrogenic differentiation. The expression of the RPLP housekeeping gene was assessed in all samples to analyse the integrity of the amplified cDNA. REL of each gene was quantified by qRTPCR. 
As shown in Figure 2C, lineage-specific genes for adipogenesis showed RELs from 13.05- to 22.21fold in hAMSCs and from 0.2- to 3.32-fold in hAECs, compared to the undifferentiated control cells. Lineage-specific genes for osteogenesis (Fig. 3C) showed REL between $6.1 \times 10^{2}$ - and $1.1 \times 10^{3}$-fold in hAECs and from $2.1 \times 10^{3}$ - to $2.9 \times 10^{3}$-fold in hAMSCs, compared to time 0 of differentiation control cells. The REL were always higher in adipogenesis and osteogenesis differentiation medium than in cells grown in DMEM for 21 days and in non-differentiated cells, with the exceptions of LPL and APM1 in hAECs. These results indicate that both populations were able to differentiate towards osteocyte-like cells; however, only hAMSCs underwent differentiation to the adipogenic lineage. In chondrogenic differentiation, both populations were able to differentiate towards chondrocyte-like cells and to express Coll II, Agg and Sox9, although their behaviours were slightly different (Fig. 4C). The hAMSCs, after culture in the chondrogenic differentiation medium, showed greater REL of the lineage-specific genes than did cells grown in DMEM for 21 days or in non-stimulated cells. In contrast, hAECs cultured in chondrogenic medium showed only a very slight increase in Coll II expression, but a decrease in Sox 9 and Agg compared to cells grown in DMEM for 21 days. These results indicate that hAMSCs could possess stronger chondrogenic differentiation than hAECs, because they express higher REL for Sox9 $(P=0.046$, Mann-Whitney $U$-test $)$ and Agg $(P>0.05$, Mann-Whitney $U$-test $)$ than hAECs.

\section{Discussion}

The amniotic membrane is the innermost membrane surrounding the foetus. Because it arises from embryonic epiblast cells prior to gastrulation, it has been suggested that it may retain a reservoir of stem cells throughout pregnancy [Ilancheran et al., 2007]. In recent years, HAMs have been used as biologic dressings for ophthalmology, plastic surgery, dermatology, and gynecology procedures [Morton and Dewhurst, 1986; Meller et al., 2000; Santos et al., 2005; Rinastiti et al., 2006; Tejwani et al., 2007]. The isolation of hAMSCs and hAECs from HAMs as a tissue source of adult MSCs has recently received great interest in the fields of cell transplantation and regenerative medicine.

In this report, we compare two distinct types of pluripotent cells isolated from HAMs to define their localization, isolated quantity, morphological and phenotypic characterization and multilineage differentiation potential. Our immunofluorescence studies indicated that the HAM contains two different cell types having stem-cell characteristics; hAMSCs from the thick basement membrane and hAECs from the single layer of ectodermally derived epithelium. For all HAM analysed, taking into account the amount of amniotic membrane used, the yield of hAECs was always higher than that of hAMSCs, indicating that the isolation and expansion protocol used produced a large number of hAECs in a short time.

The hAMSCs showed the adherence to plastic and the fibroblast-like growth usually observed in MSCs from bone marrow. Furthermore, immunophenotypic characterization of these cells demonstrated the presence of the common well defined human MSC markers (CD90, CD44, CD73, CD166, CD105 and CD29), previously described for bone marrow with the absence of the hematopoietic markers CD34 and CD45, and the concomitant lack of fibroblast markers [Kobayashi et al., 2008; Mihu et al., 2009]. This antigen expression pattern is consistent with data previously published for stem cells isolated from various regions of the full-term placenta [Bailo et al., 2004; Barlow et al., 2008; Bilic et al., 2008; Kobayashi et al., 2008; Mihu et al., 2009].

Isolated hAECs grew in a lattice structure and had the quadrangular shape typical of epithelial cells. Because they were positive for the same markers as hAMSCs, hAECs also had an antigen expression profile characteristic of culture-expanded MSCs [Bilic et al., 2008]. Phenotypes of both cell populations were maintained from passages P0 to P9. It is important to note that although both populations, hAMSCs and hAECs, showed a similar cell-surface receptor expression pattern, there were many differences between them in cell shape and cell arrangement. This is in accordance with the results of Bilic et al. 2008. These investigators also isolated these two populations and concluded that hAECs and hAMSCs in culture exhibited and maintained a similar marker profile for mesenchymal progenitors.

Statistical analyses revealed that expression levels of CD90 and CD44 were higher in the population of hAMSCs than in hAECs, whereas CD73 was higher in hAECs than in hAMSCs, in agreement with published results [Bilic et al., 2008]. Ilancheran et al. 2007 showed that hAECs expressed surface markers that are normally present on embryonic stem and germ cells, in accordance with our data that indicates that both populations in culture express the SSEA-4 and STRO-1 markers of undifferentiated cells. Both of these embryonic stem-cell markers were present in greater quantities in hAECs than in hAMSCs, as previously described by Bilic et al. 2008, possibly indicating that hAECs could be in an earlier state of undifferentiation.

MSCs from different parts of the placenta have been shown to differentiate into chondrogenic, osteogenic, endothelial, hepatocytic, myogenic and neurogenic lineages, but with appreciable differences 
among cell types depending on the placental tissue source [In't Anker et al., 2004; Sakuragawa et al., 2004; Portmann-Lanz et al., 2006; Alviano et al., 2007; Pasquinelli et al., 2007; Soncini et al., 2007; Tamagawa, 2007; Kobayashi et al., 2008; Tamagawa et al., 2008; Mihu et al., 2009; Wei et al., 2009; Chang et al., 2010; Insausti et al., 2010]. The ability of hAECs to differentiate into cardiomyocytic, myocytic, osteocytic, adipocytic (mesodermal), pancreatic, hepatic (endodermal), neural, and astrocytic (neuroectodermal) cells in vitro has been established [Miki et al., 2005, 2007; Ilancheran et al., 2007; Insausti et al., 2010]. In our study, we performed functional differentiation studies to identify which human amnion-derived cell population was associated with a greater capacity for mesodermal differentiation. We confirmed that, with stimulation, human amnion-derived cells will differentiate towards osteocytic, chondrocytic and adipocytic mesodermal lineages, indicating the presence of mesenchymal progenitors. However, we did observe some differences between the cell populations. hAMSCs showed higher adipogenic and chondrogenic potential, while hAECs showed more osteogenic differentiation capacity. Both populations retained the capacity to differentiate from culture passages P0 to $\mathrm{P} 4$, as previously described for cells from the trophoblastic region of the placenta [Fukuchi et al., 2004]. Importantly, although both populations showed similar cell-surface receptor expression patterns for mesenchymal progenitors, there were some differences in their differentiation potential. Our adipogenic differentiation results obtained with hAECs seems to be in contradiction to recent reports [Stadler et al., 2008]. It might be possible that the discrepancies in the published results with our ones could be due to the use of different cell populations with different differentiation potential [Stadler et al., 2008]. In this regard, Portmann-Lanz et al. 2006 stated that their epithelial amniotic cells underwent a transient growth retardation during which morphology changed from a typically epithelial, cobblestonelike morphology to the same fibroblast-like morphology observed with mesenchymal amniotic cells. In this regard, it has not yet been tested whether the change of morphology during hAECs cultivation originates from outgrowth of some rare hAMSCs probably present after isolation of hAECS, or from an epithelial to mesenchymal transition (EMT) of hAECs [Stadler et al., 2008].

The ability of isolated hAMSCs and hAECs to differentiate to mesodermal lineages was also assessed by qRT-PCR analysis. We studied RELs of the cytosolic fatty acid chaperone FABP4 [Xu et al., 2006], the LPL gene which is activated transcriptionally when pre-adipocytes differentiate into adipocytes [Enerbäck et al., 1992], and the APM1 gene which encodes a secretory protein of adipose tissue implicated in the pathogenesis of obesity [Schäffler et al., 1999]. These adipogenic-specific genes were expressed in hAMSCs, but not in hAECs, indicating that differentiation did not occur.

Testing lineage-specific genes for osteogenesis, we examined an early marker for osteogenesis (ALP) and the gene OP that encodes for a glycoprotein expressed in bone [Zuk et al., 2002]. hAMSCs also showed the highest REL for osteogenic differentiation, although, unlike the results for adipogenesis, both populations were able to differentiate into osteocyte-like cells. Assaying chondrogenic differentiation, we found both populations able to differentiate towards chondrocyte-like cells, but hAMSCs showed stronger chondrogenic differentiation than hAECs, as reflected by their higher REL for Sox9 and Agg than hAECs. Overall, we found hAMSCs to have higher adipogenic and chondrogenic potential than hAECs, while both populations were equally capable of differentiating into osteocyte-like cells. In general, our results are in agreement with the findings of Bilic et al. 2008, who determined the quantity and quality of amnion cells following isolation and culture and postulated that hAECs were less reliable than hAMSCs as a source of MSCs.

In conclusion, our data demonstrate the localization and successful isolation of both hAMSC and hAEC populations from HAMs. Both cell populations showed similar surface expression profiles of mesenchymal progenitors. However, they differed in cell yield and in differentiation potential to the main mesodermal lineages. Our functional differentiation studies demonstrated that hAMSCs appear to possess a much greater mesodermal differentiation capacity than hAECs, suggesting that hAMSCs contain more mesenchymal progenitor cells. These differences found in multi-lineage differentiation potential of both cell types must be taken into account when choosing the most appropriate cell type, hAMSCs or hAECs, for cell therapy to treat damaged or diseased tissues.

\section{Acknowledgements}

This study was supported by grants: Servizo Galego de Saúde, Xunta de Galicia (PS07/84), Cátedra Bioiberica de la Universidade da Coruña and Instituto de Salud Carlos III CIBER BBN CB06-01-0040. Silvia Diaz-Prado is beneficiary of an Isidro Parga Pondal contract from Xunta de Galicia, A Coruna, Spain. Emma Muíños-López is supported by the Rheumatology Spanish Foundation (SER), Spain. We would like to thank P. Filgueira and M.J. Sánchez for technical assistance. 


\section{References}

Alviano F, Fossati V, Marchionni C, Arpinati M, Bonsi L, Franchina M, Lanzoni G, Cantoni S, Cavallini C, Bianchi F, Tazzari PL, Pasquinelli G, Foroni L, Ventura C, Grossi A, Bagnara GP. 2007. Term amniotic membrane is a high throughput source for multipotent mesenchymal stem cells with the ability to differentiate into endothelial cells in vitro. BMC Dev Biol 7: 11.

Arufe MC, De la Fuente A, Fuentes-Boquete I, De Toro FJ, Blanco F. 2009. Differentiation of synovial CD-105(+) human mesenchymal stem cells into chondrocyte-like cells through spheroid formation. J Cell Biochem 108: $145-155$.

Bailo M, Soncini M, Vertua E, Signoroni PB, Sanzone S, Lombardi G, Arienti D, Calamani F, Zatti D, Paul P, Albertini A, Zorzi F, Cavagnini A, Candotti F, Wengler GS, Parolini O. 2004. Engraftment potential of human amnion and chorion cells derived from term placenta. Transplantation 78: 1439-1448.

Baksh D, Yao R, Tuan RS. 2007. Comparison of proliferative and multilineage differentiation potential of human mesenchymal stem cells derived from umbilical cord and bone marrow. Stem Cells 25: 1384-1392.

Barlow S, Brooke G, Chatterjee K, Price G, Pelekanos R, Rossetti T, Doody M, Venter D, Pain S, Gilshenan K, Atkinson K. 2008. Comparison of human placenta- and bone marrow-derived multipotent mesenchymal stem cells. Stem Cells Dev 17: 1095-1108.

Bianco P, Robey PG. 2001. Stem cells in tissue engineering. Nature 414: 118-121.

Bilic G, Zeisberger SM, Mallik AS, Zimmermann R, Zisch AH. 2008. Comparative characterization of cultured human term amnion epithelial and mesenchymal stromal cells for application in cell therapy. Cell Transplant 17: 955-968.

Chang Y-J, Hwang S-M, Tseng C-P, Cheng F-C, Huang S-H, Hsu L-F, Hsu L-W, Tsai M-S. 2010. Isolation of mesenchymal stem cells with neurogenic potential from the mesoderm of the amniotic membrane. Cells Tissues Organs 192: 93-105.

Enerbäck S, Ohlsson BG, Samuelsson L, Bjursell G. 1992. Characterization of the human lipoprotein lipase (LPL) promoter: evidence of two cis-regulatory regions, LP-alpha and LP-beta, of importance for the differentiationlinked induction of the LPL gene during adipogenesis. Mol Cell Biol 12: 4622-4633.

Fukuchi Y, Nakajima H, Sugiyama D, Hirose Y, Kitamura T, Tsuji K. 2004. Human placenta-derived cells have mesenchymal stem/progenitor cell potential. Stem Cells 22: 649-658.

GeNorm VBA applet for Microsoft Excel. 2006. [Excel macro on Internet] [cited July 2006]. Available from http://medgen.ugent.be/-jvdescomp/genorm/.

Hennerbichler S, Reichl B, Pleiner D, Gabriel C, Eibl J, Redl H. 2007. The influence of various storage conditions on cell viability in amniotic membrane. Cell Tissue Bank 8: 1-8.

Ilancheran S, Michalska A, Peh G, Wallace EM, Pera M, Manuelpillai U. 2007. Stem cells derived from human fetal membranes display multilineage differentiation potential. Biol Reprod 77: 577-588.

Ilancheran S, Moodley Y, Manuelpillai U. 2009. Human fetal membranes: A source of stem cells for tissue regeneration and repair? Placenta 30: 2-10.

In't Anker PS, Scherjon SA, Kleijburg-van der Keur C, de Groot-Swings GM, Claas FH, Fibbe WE, Kanhai HH. 2004. Isolation of mesenchymal stem cells of fetal or maternal origin from human placenta. Stem Cells 22: 13381345.

Insausti CL, Blanquer M, Bleda P, Iniesta P, Majado MJ, Castellanos G, Moraleda JM. 2010. The amniotic membrane as a source of stem cells. Histol Histopathol 25: 91-98.

Jin CZ, Park SR, Choi BH, Lee KY, Kang CK, Min BH. 2007. Human amniotic membrane as a delivery matrix for articular cartilage repair. Tissue Eng 13: 693-702.

Johnstone B, Hering TM, Caplan AI, Goldberg VM, Yoo JU. 1998. In vivo chondrogenesis of bone marrow derived mesenchymal progenitor cells. Exp Cell Res 238: 265-272.

Kim SS, Song CK, Shon SK, Lee KY, Kim CH, Lee MJ, Wang L. 2009. Effects of human amniotic membrane grafts combined with marrow mesenchymal stem cells on healing of full-thickness skin defects in rabbits. Cell Tissue Res 336: 59-66.

Kobayashi M, Yakuwa T, Sasaki K, Sato K, Kikuchi A, Kamo I, Yokoyama Y, Sakuragawa N. 2008. Multilineage potential of side population cells from human amnion mesenchymal layer. Cell Transplant 17: 291-301.

Livak KJ, Schmittgen TD. 2001. Analysis of relative gene expression data using real-time quantitative PCR and the $2^{-\Delta \Delta \mathrm{Ct}}$ method. Methods 25: 402-408.

Meller D, Pires RT, Mack RJ, Figueiredo F, Heiligenhaus A, Park WC, Prabhasawat P, John T, McLeod SD, Steuhl KP, Tseng SC. 2000. Amniotic membrane transplantation for acute chemical or thermal burns. Ophthalmology 107: $980-989$

Mihu CM, Rus Ciucă D, Soritău O, Suşman S, Mihu D. 2009. Isolation and characterization of mesenchymal stem cells from the amniotic membrane. Rom J Morphol Embryol 50: 73-77.

Miki T, Lehmann T, Cai H, Stolz DB, Strom SC. 2005. Stem cell characteristics of amniotic epithelial cells. Stem Cells 23: 1549-1559.

Miki T, Marongiu F, Ellis E, Strom SC. 2007. Isolation of amniotic epithelial stem cells. Curr Protoc Stem Cell Biol 1E.3: 1E.3.1-1E.3.9.

Minguell JJ, Conget P, Erices A. 2000. Biology and clinical utilization of mesenchymal progenitor cells. Braz J Med Biol Res 33: 881-887.

Morton KE, Dewhurst CJ. 1986. Human amnion in the treatment of vaginal malformations. Br J Obstet Gynaecol 93: $50-54$. 
Niknejad H, Peirovi H, Jorjani M, Ahmadiani A, Ghanavi J, Seifalian AM. 2008. Properties of the amniotic membrane for potential use in tissue engineering. Eur Cell Mater 15: 88-99.

Pasquinelli G, Tazzari P, Ricci F, Vaselli C, Buzzi M, Conte R. 2007. Ultrastructural characteristics of human mesenchymal stromal (stem) cells derived from bone marrow and term placenta. Ultrastruc Pathol 31: 23-31.

Portmann-Lanz CB, Schoeberlein A, Huber A, Sager R, Malek A, Holzgreve W, Surbek DV. 2006. Placental mesenchymal stem cells as potential autologous graft for pre- and perinatal neuroregeneration. Am J Obstet Gynecol 194: 664-673.

Rinastiti M, Harijadi Santoso AL, Sosroseno W. 2006. Histological evaluation of rabbit gingival wound healing transplanted with human amniotic membrane. Int J Oral Maxillofac Surg 35: 247-251.

Roche Applied Science. 2008. [database on the Internet] [cited February 20, 2008]. Assay Design Center/ProbeFinder. Homo sapiens (Human). Available from Roche Applied Science [database on the Internet] [cited February 20, 2008].

Sakuragawa N, Kakinuma K, Kikuchi A, Okano H, Uchida S, Kamo I, Kobayashi M, Yokoyama Y. 2004. Human amnion mesenchyme cells express phenotypes of neuroglial progenitor cells. J Neurosci Res 78: 208-214.

Sambrook J, Maniatis T, Fritsch EF. 1989. Molecular cloning: A laboratory manual. New York: Cold Spring Harbor Laboratory Press.

Santos MS, Gomes JAP, Hofling-Lima AL, Rizzo LV, Romano AC, Belfort R, Jr. 2005. Survival analysis of conjuctival limbal grafts and amniotic membrane transplantation in eyes with total limbal stem cell deficiency. Am J Ophthalmol 140: 223-230.

Schäffler A, Orsó E, Palitzsch KD, Büchler C, Drobnik W, Fürst A, Schölmerich J, Schmitz G. 1999. The human apM-1, an adipocyte-specific gene linked to the family of TNF's and to genes expressed in activated T cells, is mapped to chromosome 1q21.3-q23, a susceptibility locus identified for familial combined hyperlipidaemia (FCH). Biochem Biophys Res Commun 260: 416-425.

Soncini M, Vertua E, Gibelli L, Zorzi F, Denegri M, Albertini A, Wengler GS, Parolini O. 2007. Isolation and characterization of mesenchymal cells from human fetal membranes. J Tissue Eng Regen Med 1: 296-305.

Stadler G, Hennerbichler S, Lindenmair A, Peterbauer A, Hofer K, Van Griensven M, Gabriel C, Redl H, Wolbank S. 2008. Phenotypic shift of human amniotic epithelial cells in culture is associated with reduced osteogenic differentiation in vitro. Cytotherapy 10: 743-752.

Tamagawa T. 2007. Differentiation of mesenchymal cells derived from human amniotic membranes into hepatocytelike cells in vitro. Hum Cell 20: 77-84.

Tamagawa T, Ishiwata I, Ishikawa H, Nakamura Y. 2008. Induced in vitro differentiation of neural-like cells from human amnion-derived fibroblast-like cells. Hum Cell 21: 38-45.

Tejwani S, Kolari RS, Sangwan VS, Rao GN. 2007. Role of amniotic membrane graft for ocular chemical and thermal injuries. Cornea 26: 21-26.

Toda A, Okabe M, Yoshida T, Nikaido T. 2007. The potential of amniotic membrane/amnion-derived cells for regeneration of various tissues. J Pharmacol Sci 105: 215-228.

Tsai MS, Hwang SM, Chen KD, Lee YS, Hsu LW, Chang YJ, Wang CN, Peng HH, Chang YL, Chao AS, Chang SD, Lee KD, Wang TH, Wang HS, Soong YK. 2007. Functional network analysis on the transcriptomes of mesenchymal stem cells derived from amniotic fluid, amniotic membrane, cord blood, and bone marrow. Stem Cells 25: 2511-2523.

Universal ProbeLibrary. 2008. Universal ProbeLibrary interest site. Assay Design Center/ProbeFinder. Homo sapiens (Human). Available from http://www.roche-applied-science.com.

Wei JP, Nawata M, Wakitani S, Kametani K, Ota M, Toda A, Konishi I, Ebara S, Nikaido T. 2009. Human amniotic mesenchymal cells differentiate into chondrocytes. Cloning Stem Cells 11: 19-25.

Wilshaw SP, Kearney JN, Fisher J, Ingham E. 2006. Production of an acellular amniotic membrane matrix for use in tissue engineering. Tissue Eng 12: 2117-2129.

Wolbank S, Peterbauer A, Fahrner M, Hennerbichler S, van Griensven M, Stadler G, Redl H, Gabriel C. 2007. Dosedependent immunomodulatory effect of human stem cells from amniotic membrane: A comparison with human mesenchymal stem cells from adipose tissue. Tissue Eng 13: 1173-1183.

Xu A, Xu A, Wang Y, Xu JY, Stejskal D, Tam S, Zhang J, Wat NM, Wong WK, Lam KS. 2006. Adipocyte fatty acid-binding protein is a plasma biomarker closely associated with obesity and metabolic syndrome. Clin Chem 52: 405-413.

Zuk PA, Zhu M, Ashjian P, De Ugarte DA, Huang JI, Mizuno H, Alfonso ZC, Fraser JK, Benhaim P, Hedrick MH. 2002. Human adipose tissue is a source of multipotent stem cells. Mol Biol Cell 13: 4279-4295. 